different groups of SWs. Some STIs are more prevalent among SWs than the general public. However, these results should be interpreted with caution as the identifying SW code is new and inconsistencies in the way SWs are identified were observed.

\section{P3.175 PREVALENCE OF HIV, SYPHILIS, DRUGS USE AND SEXUAL RISK BEHAVIOURS AMONG PRISONERS IN GUATEMALA, 2012}

doi:10.1136/sextrans-2013-051184.0632

'B E Alvarez Rodríguez, ${ }^{2} Z$ Pinzón, 'B J Huaman, ${ }^{3} \mathrm{M}$ Mansur, ${ }^{3} \mathrm{R}$ Vega, ${ }^{3} \mathrm{~S}$ Ortega, 4 Osuna-Ramírez, 'I Loya-Montiel, 'N Arambu, 'S Morales-Miranda. 'Universidad del Valle de Guatemala, Guatemala, Guatemala; ${ }^{2}$ Programa Nacional de VIH/SIDA, Ministerio de Salud de Guatemal, Guatemala, Guatemala; 3/nstituto Humanista de Cooperación para el Desarrollo (HIVOS), Guatemala, Guatemala; ${ }^{4}$ Universidad Autonoma de Sinaloa, Culiacan-Sinaloa, Mexico

Background In Guatemala, there is limited information on the situation of HIV in prisoners. Therefore performed the first representative Behavior Surveillance Survey (BSS) and Prevalence of HIV and syphilis conducted among inmate population in country.

Methods From September to December 2012, inmates were recruited in 6 prisons located in Guatemala City. A two-stage random cluster sampling and a face-to-face standardised questionnaire were applied. Those who met eligibility criteria and signed informed consent were selected as participants, being all of them tested for HIV and syphilis. The proportions, medians, interquartile range (IOR) and confidence intervals (CI: 95\%) were obtained using STATA 11.1.

Results 605 inmates wererecruited, $87 \%$ male/13\% female. The median age was 31 years (IOR 25-38). 50\% had 1-5 years of imprisonment; the median was 2 years (IOR $0.8-4$ ). Nearly $30 \%$ reported $>2$ sexual partners in the last 12 months; only $23 \%$ used a condom at last intercourse. Consistent condom use in the past 30 days with regular partner, casual and business was 13\%, 43\%, 78\% respectively. The $51 \%$ and $58 \%$ reported illicit drug use at some time- in life and in the last 30 days, $5 \%$ and $1 \%$ used injection drugs in the same periods respectively. The Index of adequate knowledge about HIV was $32 \%$. The prevalence of HIV was $0.76 \%$ (CI $0.24-1.76$ ) and syphilis $3.5 \%$ (CI: 2.23-5.20).

Conclusions A low HIV prevalence and syphilis among inmates in Guatemala were found. However, sexual risk behaviours and low HIV knowledge put them at risk of HIV infection. Drug use was higher than reported in other Central American BSS $(<1 \%)$. It is necessary that the state as guarantor of inmates ensures access to prevention and control of STIs and HIV, emphasising the use of condoms in all sexual relations and the use of sterile injecting equipment for intravenous drug users.

\section{P3.176 PREVALENCE OF GENITAL INFECTIONS WITH CHLAMYDIA TRACHOMATIS (CT), NEISSERIA GONORRHOEA (NG) AND TRICHOMONAS VAGINALIS (TV) IN HARD-TO-REACH FEMALE SEX WORKERS IN NORTH RHINE-WESTPHALIA, GERMANY: THE STI-OUTREACH STUDY}

doi:10.1136/sextrans-2013-051184.0633

${ }^{1,2} \mathbf{K}$ Jansen, ${ }^{1,2} \mathrm{~V}$ Bremer, ${ }^{1} \mathrm{G}$ Steffen, ${ }^{1} \mathrm{~N}$ Sarma, ${ }^{3} \mathrm{D}$ Münstermann, ${ }^{3} \mathrm{~A}$ Lucht, ${ }^{3} \mathrm{C}$ Tiemann. ${ }^{1}$ Robert Koch-Institute, Berlin, Germany; ${ }^{2}$ German STI Society, Bochum, Germany; ${ }^{3}$ Labor Krone, Bad Salzuflen, Germany

Background In Germany, few data exist about the prevalence of STI in female sex workers (FSW). Especially hard-to-reach populations without regular contact to health services may be at high risk for STI. We measured the prevalence of CT, NG and TV among FSW at their workplace in order to evaluate whether these tests should be routinely offered in this population.

Methods Specialised outreach-workers of local public health authorities (LPHA) screened FSW in North Rhine-Westfalia for the respective STI on basis of self-collected vaginal swabs, using TMA (CT and NG: APTIMA Combo $2^{\circledR}$; TV: APTIMA ${ }^{\circledR}$ Trichomonas vaginalis Assay). Sociodemographics, sexual behaviour, and medical care situation were surveyed with help of translators and cultural mediators.

Results Up to February 8, 227 FSW were enrolled by 9 LPHA. $10.6 \%$ of FSW were born in Germany, $27.8 \%$ in Bulgaria, $22.5 \%$ in Romania, $39.1 \%$ in other countries. $40.9 \%$ of non-Germans had no German language skills. German and non-German FSW differed significantly regarding mean age ( 35 years vs. 30 years, $p<0.01$ ), mean duration of sex work (8.7 years vs. 3.6 years, $p<0.01$ ), existing health insurance for Germany $(91.7 \%$ vs. $18.6 \%, p<0.01)$, and ever attending a LPHA (62.5\% vs. $32.5 \%, p=0.016)$.

Overall prevalences were $7.9 \%$ for CT, $12.8 \%$ for NG, and $16.3 \%$ for TV (table 1).

Conclusion For the first time, hard-to-reach FSW were screened for CT, NG, and TV in a low threshold multicenter approach in Germany. Lacking German language skills, no health insurance, rare contact to LPHA, and mostly foreign origin characterised a large proportion of the study population, but nearly all these factors were independent from being tested positively for STI. We found high prevalences of CT, NG, and TV demonstrating a high

Abstract P3.176 Table 1 Sociodemographic and behavioural characteristics of female sex workers tested for Neisseria gonorrhoea, Chlamydia trachomatis and Trichomonas vaginalis within the STI-Outreach study (for comparisons: chi-square test or Fisher's exact test, where appropriate)

\begin{tabular}{|c|c|c|c|c|c|c|c|c|c|c|}
\hline & & \multicolumn{3}{|c|}{ Neisseria gonorrhoea } & \multicolumn{3}{|c|}{ Chlamydia trachomatis } & \multicolumn{3}{|c|}{ Trichomonas vaginalis } \\
\hline & & $\begin{array}{l}\text { Positive } \\
(\mathrm{n}=18)\end{array}$ & $\begin{array}{l}\text { negative } \\
(n=209)\end{array}$ & p-value & $\begin{array}{l}\text { Positive } \\
(n=29)\end{array}$ & $\begin{array}{l}\text { negative } \\
(\mathrm{n}=198)\end{array}$ & p-value & $\begin{array}{l}\text { Positive } \\
(\mathrm{n}=37)\end{array}$ & $\begin{array}{l}\text { negative } \\
(n=190)\end{array}$ & p-value \\
\hline \multirow[t]{4}{*}{ Age (years) } & $<20$ & 0 & 1.9 & 0.273 & 0 & 2.0 & 0.188 & 2.7 & 1.6 & 0.428 \\
\hline & $20-29$ & 77.8 & 54.1 & & 72.4 & 53.5 & & 64.9 & 54.2 & \\
\hline & $30-39$ & 11.1 & 29.2 & & 24.1 & 28.3 & & 24.3 & 28.4 & \\
\hline & $>40$ & 11.1 & 14.8 & & 3.5 & 16.2 & & 8.1 & 15.8 & \\
\hline \multirow[t]{2}{*}{ Country of birth } & Germany & 0 & 11.5 & 0.229 & 6.9 & 11.1 & 0.747 & 2.7 & 12.1 & 0.140 \\
\hline & Abroad & 100 & 88.5 & & 93.1 & 88.9 & & 97.3 & 87.9 & \\
\hline \multirow[t]{2}{*}{ German language skills (only foreigners) } & Fluent/Basic & 16.7 & 63.2 & 0.000 & 59.3 & 59.1 & 0.987 & 47.2 & 61.7 & 0.110 \\
\hline & None & 83.3 & 36.8 & & 40.7 & 40.9 & & 52.8 & 38.3 & \\
\hline \multirow[t]{2}{*}{ Ever attended LPHA? } & Yes & 16.7 & 37.3 & 0.122 & 24.1 & 37.4 & 0.165 & 37.8 & 35.3 & 0.765 \\
\hline & No/not sure & 83.3 & 62.7 & & 75.9 & 62.6 & & 62.2 & 64.7 & \\
\hline \multirow[t]{2}{*}{ Health insurance valid for Germany? } & Yes & 5.6 & 27.8 & 0.048 & 13.8 & 27.8 & 0.119 & 16.2 & 27.9 & 0.138 \\
\hline & No/not sure & 94.4 & 72.2 & & 86.2 & 72.8 & & 83.8 & 72.1 & \\
\hline
\end{tabular}

